\title{
ANNOUNCEMENT REGARDING 1943 MEETING
}

A FEW members have raised questions regarding the policy of continuing to plan for the Twentieth Annual Meeting, scheduled to be held at the Hotel Pennsylvanla, February 22, 23, 24. Those few who question the advisability of holding the meeting seem to fear that the Association will be criticized if we go ahead with plans, even though no rules have been set up by responsible officials to determine exact limitations on meetings.

One argument advanced by a particularly vigorous critic is that all other societies of which he is a member have cancelled their meetings. What bearing this may have on us or on the many other societies, associations, organizations and legions which have not cancelled their meetings is, to say the least, unclear. In the case of certain organizations, meetings have been cancelled because a large proportion of the membership was in the armed services and meetings seemed impractical. This does not apply to us, although we too have many members in the services.

Members of the Board discussed this whole matter early in the summer and it was decided to go ahead with plans for the meeting for quite simple, obvious reasons. One is that it is difficult to see how a New York meeting can possibly put much strain on transportation facilities-nothing, for example, such as the load imposed by state and national medical societies, Veteran's organizations and other groups which have not altered their plans for meetings.

A New York meeting of our Association draws about 80 per cent of its total attendance from among those who live in, or habitually travel to, New York; and the figures are about the same for members. At the I94I meeting, attended by over 1700 registrants, there were 21 I members of whom 50 per cent were local, an additional 20 per cent from nearby points, and only 30 per cent travelled 400 miles or more to the meeting. It seems unlikely, therefore, that the number of members who would wish to attend would greatly strain transportation facilities which, while heavily burdened, are by no means carrying only essential people on mandatory errands. Even with conceivable further uniform restrictions on railroad travel such that members living at any distance would be definitely unable to attend, there would still be a large and representative non-travelling group to whom the papers and discussions should be of great value. In other words, the restriction in travel will not apply to very many who might otherwise like to attend.

Those prohibited from attending, though desiring to do so, might raise questions regarding the protection of their right to vote on various issues. The only answer is that the usual safeguards will be continued. It may be pointed out that these were invented because attendance by members is never large, rarely reaching as high as 40 per cent of the membership and only once, in I $94 \mathrm{I}$, comprising more than half the membership ( $57 \%$ ). Fact is, of course, that the eastern sea-board from Boston to Washington comprises about half of our total membership, there being approximately 30 per cent in Metropolitan New York alone. 
So, as usual, all members will receive by mail lists of nominations for office, of candidates for election to membership, of nominations for fellowship, any proposed amendments to the By-laws, such other proposals as may require voting, and study-committee reports which may require study or action. In the past, very fe'v members have taken the trouble to return these lists with their votes. Perhaps the knowledge of transportation difficulties this year will cause more members to read these proposals and vote by mail. (Indeed, it might be a salutary thing if we operated under a rule which provided that votes not returned by mail should be counted in the affirmative, subject to some sort of approval by members present and voting at the formal business session.)

The Board naturally recognized that any of several developments might call for changes in plans, even cancellation of the meeting. Thus, should New York become a combat area, or classed as a no-travel zone, or other military necessities intervene, then appropriate and requisite action would be taken. One can not know now that the meeting will in any way interfere with the war effort; until that is clear, the only logical thing to do is to proceed with plans.

The point has also been made that if it is felt by the officers that the meeting is "essential for the war effort," this is "a grandiose delusion." This is the opinion of one who thinks that many individual members are essential to the war effort, but the meetings are not. While many members have expressed an opposite point of view, this particular matter of essentialness has not been discussed by the Board, nor is it likely that it will be, since it seems, at least to the Editor, to be somewhat irrelevant. A more important question might be, why should the meeting not be held? Surely no one would claim that the meeting in any way jeopardizes the war effort.

Actually, the point seems specious. What is essential to the war effort? Who determines it? How is it carried out? And does anything need to be directly a part of the war effort to be valuable to its promotion, the furtherance of its aims and the long range picture? The important question seems to be whether something proposed has values for one or more aspects of the war effort, of which civilian health and morale are certainly important. Those of us who are not directly engaged in the war effort have our perplexing duties and responsibilities concerning which we need the opportunity to confer, precisely as heretofore. Many have expressed the view that this year, more than ever, there is need to get together and discuss many common problems relating to the war and its effects in many directions. Furthermore, with a program geared to the problems of a war-torn world, there should be much to offer in THE JournaL to others who are in the armed forces and unable to attend such meetings. It does not seem necessary to think of the meeting as "essential" to the war effort directly; if it will help us better to do our jobs, whatever they may be, it will contribute to the efficiency of the contributions we are all called on to make to that effort.

What of the problem of aggression? We are all of us participating spectators of the most massive aggression, motivated largely by hostility, which has ever been the unfortunate lot of society. What do we know of its treatment? Of its 
aftercare? What philosophy can we draw from clinical experience of several kinds to assist in broader social planning? Can hostile aggression en masse ever be dealt with otherwise than by superior force? There are here a series of problems for discussion at this meeting.

Or, consider questions concerning the mental hygiene of childhood in a period of this sort. There have been rather wide variations of experience, and even wider variations of opinion and of practice. There is the English experience, available to us now in fair detail. In this country, all sorts of planning, and even execution of plans, have been carried out, often without benefit of mental hygiene advice. There are committees galore-but what are they doing? And how are they being coordinated?

All our experiences need to be brought together and some unified concepts of general principles evolved. Where can that be done except at such a meeting as ours? Isn't it essential to our functioning? Or can it be that neither as individuals nor as an organization we have a function? Hardly! So let us make the meeting a most important tool for our further work, and express regrets to those who, for one reason or another, will be unable to attend.

L. G. L. 